21 Maeda S, Abe A, Seishima M, Makino K, Noma A, Kawade M. Transien changes of serum lipoprotein(a) as an acute phase protein. Atherosclerosis 1989;78:145-50

22 Sundell IB, Nilsson TK, Hallmans G, Hellsten G, Dahlén GH. Interrclationships between plasma levels of plasminogen activator inhibitor, tissue plasminogen activator, lipoprotein(a) and established cardiovascular risk factors in a north Swedish population. Atherosclerosis 1989;80:9-16.

23 Durrington PN, Ishola M, Hunt L, Arrol S, Bhatnagar D. Apolipoprotein (a) AI, and B and parental history in men with early onset ischaemic hear disease. Lancet 1988; i: 1070-3.

24 Hoefler G, Harnoncourt F, Paschke E, Mirtl W, Pfeiffer KH, Kostner GM Lipoprotein Lp(a). A risk factor for myocardial infarction. Arteriosclerosis 1988:8:398-401.
25 Seed M, Hoppichler F, Reaveley D, et al. Relation of serum lipoprotein(a) concentration and apolipoprotein (a) phenotype to coronary heart disease in patients with familial hypercholesterolemia. $N$ Engl f Med 1990;322: $1494-9$

26 Carlson LA, Hamsten A, Asplund A. Pronounced lowering of serum levels of lipoprotein(a) in hyperlipidaemic subjects treated with nicotinic acid f Intern Med 1989;226:271-6.

27 Masarei JRL, Rouse IL, Lynch WJ, Robertson K, Vandongen R, Beilin LJ. Effects of a lacto-ovovegetarian diet on serum concentrations of cholesterol, triglyceride, $\mathrm{HDL}-\mathrm{C}, \mathrm{HDL}_{2}-\mathrm{C}, \mathrm{HDL}_{3}-\mathrm{C}$, apoprotein-B and $\mathrm{Lp}(\mathrm{a}) . A m \mathcal{f}$ Clin Nutr 1984;40:468-79.

(Accepled 11 Seplember 1990)

\title{
Ear wax removal: a survey of current practice
}

\author{
J F Sharp, Janet A Wilson, Linda Ross, R M Barr-Hamilton
}

TABLE I - Number of patients presenting for ear wax removal to 289 general practitioners

\begin{tabular}{lc}
\hline $\begin{array}{l}\text { Patients seen } \\
\text { per month }\end{array}$ & $\begin{array}{c}\text { No of general } \\
\text { practitioners }\end{array}$ \\
\hline $0-5$ & 7 \\
$6-10$ & 133 \\
$11-20$ & 101 \\
$21-50$ & 31 \\
$\geqslant 51$ & 4 \\
No reply & 13 \\
\hline
\end{tabular}

\section{Department of}

Otolaryngology, Royal

Infirmary, Edinburgh EH3 9EN

J F Sharp, FRCSED, registrar

Janet A Wilson, FRCSED, senior registrar

Linda Ross, SRN, sister

Department of Audiology, Royal Infirmary, Edinburgh EH3 9EN

R M Barr-Hamilton, PHD, principal audiological scientist

Correspondence to: $\mathrm{Dr}$ Sharp.

BrMed F 1990;301:1251-3

\section{Abstract}

Objective-Todetermine the methods of removing ear wax used by local general practitioners and the incidence of associated complications.

Design-Postal survey of 312 general practitioners serving a population of about 650000 ; supplementary study of ear, nose, and throat outpatients to quantify the improvement in aural acuity after wax removal.

Setting-Catchment area of the Edinburgh otolaryngological unit.

Participants-289 General practitioners who responded to the survey; 21 outpatients in the ear, nose, and throat department with occlusive wax.

Results-274 General practitioners removed wax by syringing, but only $53(19 \%)$ always performed the procedure themselves; the remainder routinely delegated the task to practice nurses, some of whom had received no instruction. Ears were rarely examined again after the procedure. Complications had been experienced by 105 practitioners (38\%) and included perforation, canal lacerations, and failure of wax removal. The removal of occlusive wax improved hearing by a mean of $5 \mathrm{~dB}$ over the frequencies analysed.

Conclusions-About 44000 ears are syringed each year in the area and complications requiring specialist referral are estimated to occur in 1/1000 ears syringed. The incidence of complications could be reduced by a greater awareness of the potential hazards, increased instruction of personnel, and more careful selection of patients.

\section{Introduction}

Ear wax removal is the otolaryngological procedure most commonly performed by general practitioners and is their commonest source of iatrogenic otolaryngological problems. ${ }^{1}$ Modern otolaryngological textbooks do not often refer to ear syringing, ${ }^{2}$ and the indications and optimum methods for aural wax removal are not known. Wax may cause tinnitus or otalgia and removal may be required to allow adequate otoscopic examination, but many patients with a sensorineural hearing loss request repeated ear syringings in the mistaken belief that these will restore auditory acuity. Potential complications include perforation, otitis externa, vertigo, and cardiac arrest. ${ }^{3}$ We have recently seen several outpatients from the ear, nose, and throat department who had complications of ear syringing, including a temporal lobe abscess. This prompted a survey of the methods of ear wax removal and the incidence of complications in the community.

\section{Methods}

A postal survey was carried out in the Lothian area. Three hundred and twelve general practitioners serving a population of about 650000 were questioned. Doctors were asked to complete a short questionnaire with items on the number and selection of patients seeking wax removal, the methods used, complications encountered, and respondent's perception of any effect on auditory acuity. A supplementary survey to quantify the degree of improvement in auditory acuity after wax removal was conducted in the ear, nose, and throat outpatient clinic. Twenty one unselected outpatients who presented with completely occlusive aural wax were assessed by pure tone audiometry before and after wax removal by syringing. The ears were inspected after syringing and any residual water removed. The audiometric testing was performed according to the recommended procedures of the British Society of Audiology. The effect of syringing on aural acuity was measured by determining hearing thresholds at 250 and $500 \mathrm{~Hz}$ and 1,2 , and $4 \mathrm{kHz}$ before and after wax removal. A paired $t$ test comparing the means of the five frequencies was then performed.

\section{Results}

The 289 replies received (92\% of the study group) indicated that each doctor saw an average of nine patients (range five to 50 or more) requesting the removal of ear wax per month (table I). The initial medical assessment was made by 179 general practitioners $(62 \%)$. No medical assessment was made by $23(8 \%)$; these patients were referred directly to the practice nurse. The remaining $87(30 \%)$ offered examination by either the doctor or nurse. Table II shows the variety of ceruminolytic agents used.

As expected, syringing was the most common method of removal and was used by 274 general practitioners $(95 \%)$. Twelve $(4 \%)$ used instrumentation (a Jobson Horne probe) as their initial method of wax removal. Three (1\%) referred their patients directly to the outpatient clinic. Only 53 general practitioners (19\%) always performed the syringing procedure themselves; the practice nurse routinely syringed the ears of all patients referred to 73 general practitioners $(27 \%)$. The remaining 148 practitioners

TABLE II -Ceruminolytics prescribed by general practitioners (55 used several preparations)

\begin{tabular}{lcc}
\hline Preparation & $\begin{array}{c}\text { No of general } \\
\text { practitioners }\end{array}$ & Unit cost (pence) \\
\hline Oil & 233 & 7 \\
Cerumol & 43 & 83 \\
Bicarbonate & 27 & 2 \\
Exterol & 10 & 235 \\
Waxsol & 6 & 86 \\
Soliwax & 5 & 73 \\
Earex & 3 & \\
"Proprietary preparation" & 3 & 79 \\
Glycerine & 1 & \\
None & 13 & \\
\end{tabular}


TABLE III-Complications of ear syringing reported by 105 general practitioners

\begin{tabular}{lc}
\hline Failure of wax removal & 37 \\
Otitis externa & 22 \\
Perforation of tympanic membrane & 19 \\
Damage to external auditory canal & 15 \\
Pain & 10 \\
Vertigo & 9 \\
Otitis media & 5 \\
Perforation discovered-pre-existing? & 4 \\
Not specified & 6 \\
\hline Total & 127
\end{tabular}

$(54 \%)$ allowed syringing by the team member, either doctor or nurse, who had initially assessed the patient. Not all patients whose ears had been syringed by the nurse were re-examined by the general practitioners (87 $(32 \%)$ did not inspect the ears after wax removal). Complications of syringing had been encountered by $105(38 \%)$ general practitioners (table III). Most general practitioners (263) believed that wax removal aided auditory acuity, but 74 doctors thought that removal helped hearing only if the wax was impacted and occulusive. Seventeen general practitioners who did not believe that wax removal aided hearing continued to perform the procedure.

The mean increase in hearing thresholds after wax removal in the 21 outpatients was $5.45 \mathrm{~dB},(95 \%$ confidence interval 0.59 to $10.47 \mathrm{~dB} ; \mathrm{p}=0.03$ ). Most of these patients had a moderate to severe high frequency sensorineural hearing loss.

\section{Discussion}

The removal of ear wax has been practised since the ancient Egyptians syringed suppurating ears with olive oil, frankincense, and salt. ${ }^{4}$ Other historical remedies include the injecton of goat urine and gall and the instillation of steam. ${ }^{5}$ The results of the present study indicate that each year at least 44000 ears are syringed in the Lothian area. Though the frequency of syringing reported in the present study is only an estimate made by the participating general practitioners, the average figure of nine patients per month per doctor confirms Burgess's finding that general practitioners syringe about two patients a week. ${ }^{6}$

The high response rate (92\%) suggests a high level of interest by general practitioners in this common problem, for which there are few current guidelines. The removal of occlusive wax may be necessary if it prevents a thorough examination of the ear, especially in patients complaining of pain. Cerumen was found to occlude completely one in eight of the externatauditory meatuses in a random sample of 800 people, ${ }^{7}$ a finding that may or may not be related to the use of cotton buds. ${ }^{8-11}$ The commonest reason for wax removal was a complaint of hearing impairment, although hearing loss is often sensorineural and the procedure is of limited benefit to auditory acuity.

The desire of individual patients to be, as it were, "wax free" should not be underestimated. Many patients harbour the misconception that wax is a pathological secretion and that its mere presence is an indication for removal. There is little doubt that this attitude contributes greatly to the amount of syringing that we have observed.

Our results show a $5 \mathrm{~dB}$ increase in auditory acuity for the frequencies analysed after the syringing of occlusive wax. This is a small improvement but may be sufficient to allow a patient whose hearing thresholds border on the requirement for a hearing aid to be able to function socially without auditory amplification.

Many agents were used to soften wax before syringing. In vitro experiments with wax solvents give a poor indication of their clinical efficacy. ${ }^{12}$ Oil was the ceruminolytic agent prescribed most often and

\section{Ear syringing}

Indications

- Totally occlusive wax

- Pain

- Unilateral reduction in acuity

- Examination of obscured tympanic membrane

- Tinnitus

- Otitis externa (if dry mopping facilities available)

\section{Contraindications}

- Non-occlusive wax

- Previous ear surgery

- Only hearing ear

- Age under 16 years

- History of otitis externa

\section{Method}

- Wax solvent for 7 days (preferably almond oil or olive oil)

- Water at $37^{\circ} \mathrm{C}$

- Check that syringe is functioning smoothly

- Protect the patient with a plastic sheet to collect water

- Direct water jet towards occiput (not directly on to tympanic membrane)

- Inspect canal after syringing and inquire about side effects

Cerumol was the proprietary solution used most often. Cerumol has been shown to be significantly more effective than bicarbonate solution and marginally better than olive oil or Waxsol in aiding wax removal. ${ }^{1314}$ Xerumenex has been shown to be no better than olive oil, ${ }^{15}$ and a multicentre trial found Exterol (5\% urea-hydrogen peroxide in glycerol) to be significantly more effective than either glycerol or Cerumol. ${ }^{16}$ Despite this finding, Exterol is rarely advocated, perhaps because of its greater cost (table I).

Most general practitioners syringe wax from the canal with a traditional syringe, which can develop pressures of up to $16 \mathrm{kPa}$ (110 psi). A few use other water irrigation methods, including dental irrigation systems such as the Water Pik. ${ }^{17}$ It is important that the person performing the syringing is fully instructed in the technique. Five general practitioners did not know if their nurses had been instructed in the method of ear syringing.

The referral rate to our department of patients with complications after syringing suggests a rate of major complications of $1 / 1000$ ears syringed. It is important to inspect the ear after syringing to ensure that all the wax has been removed and that the ear drum has not been perforated, yet such inspection was performed by only $68 \%$ of doctors. The range of complications encountered after this procedure is well recognised by otolaryngologists, ' but some general practitioners were unaware of any potential hazards and noted their surprise on the questionnaire. Thus many general practitioners did not inspect the ear after syringing.

We conclude that syringing can result in an improvement in auditory acuity of up to $5 \mathrm{~dB}$ but also that a greater awareness of potential hazards of syringing is needed. The adoption of a more selective approach to removal of ear wax (see box) could reduce iatrogenic ear disease.

Morrison AW. Silence in court. $\mathcal{F}$ Laryngol Otol 1990;104: 162-5.

2 Shenoi PM. Management of chronic suppurative otitis media. In: Booth JB ed. Scott Brown's otolaryngology. 5th ed. Vol 3. London: Butterworth, 1987:215-37.

3 Prasad KS. Cardiac depression on syringing the ear. I Laryngol Oto $1984 ; 98: 1013$.

Stevenson RS, Guthrie D. A history of otolaryngology. Edinburgh; Livingstone. 1949:8.

5 Cleland A Instruments to remedy some kinds of deafness. Philosophical Transactions of the Roval Society of London 1741;41:848-51. 
6 Burgess EH. Ear wax - and the right way to use an ear syringe. Nursing Times $1977 \cdot 73 \cdot 156+-5$

7 Hinchcliffe R. Prevalence of the commoner ear, nose and throat conditions in the adult rural population of Great Britain. British fournal of Preventive and Social Medicine 1961:15:128-40.

8 Warwick-Brown NP. Wax impaction in the ear. Practitioner 1986;230:301

9 Anonymous. Wax in the ear [Editorial]. Br.Med f 1972;iv:623-4.

10 Mevers AD. Practical ENT: managing cerumen impaction. Postgrad Med 1977;62:207-9.

11 Sim DW. Wax plugs and cotton buds. F Larvngol Otol 1988; 102:575-6.

12 Horowitz JI. Solvents for ear wax. Br.Med f 1968;iv:583.
13 Fraser JG. The efficacy of wax solvents: In vitro studies and a clinical trial. f Laryngol Otol 1970;84:1055-64.

14 Anonymous. Ear wax solvents compared. Drug Ther Bull 1971;9:15-6

15 Chaput de Saintonge DM, Johnstone CI. A clinical comparison of triethanot amine polypeptide oleatecondensate ear drops with olive oil for the removal of impacted wax. Brf Clin Practice 1973;27:454-5.

16 Fahmey S, Whitefield M. Multicentre clinical trial of Exterol as a cerumenolytic. Br f Clin Pract 1982;36: 197-204

17 Seiler ER. Ear syringing. Br Med f 1980;280:1273.
Royal Hospital for Sick Children, Glasgow G3 8SJ Fiona A Logan, MRCPSYCH, research registrar

A Maclean, MAPPSCI, senior clinical psychologist, department of child and family psychiatry

B Gibson, MRCPATH, consultant haematologist

Department of Haematology, The Hospitals for Sick Children, London I M Hann, MD, consultant haematologist

University of Glasgow, Glasgow

C A Howie, BSC, statistician, department of materia medica W L Parry-Jones, FRCPSYCH, professor of child and adolescent psychiatry

Correspondence to: Dr F A Logan, Westcotes House, Westcotes Drive, Leicester LE3 0QU.

BrMed f 1990;301:1253-6

\title{
Psychological disturbance in children with haemophilia
}

\author{
Fiona A Logan, A Maclean, C A Howie, B Gibson, I M Hann, W L Parry-Jones
}

\section{Abstract}

Objective-To assess the need for formal psychotherapeutic intervention in children attending a children's haemophilia clinic after some of them had been diagnosed as positive for HIV.

Design-Comparison of haemophiliac children with matched control groups of diabetic and healthy children.

Setting-The West of Scotland Children's

Haemophilia Centre, Glasgow.

Patients -43 Children aged 3 to 16 years with mild, moderate, and severe clotting disorders were matched with control groups of $\mathbf{4 6}$ diabetic children and 42 physically healthy children.

Interventions - Parents of children aged 3-5 years were interviewed with the behaviour screening questionnaire. Children aged 6 to 16 were assessed by parental and teacher report using standardised questionnaires and self report using a computerised depression inventory. All were scored numerically according to the presence of symptoms of emotional and behavioural problems.

Main outcome measures-The groups were compared for mean scores on each rating device and for number of children achieving scores within the pathological range.

Results - In the 6-16 age group five haemophiliac children, five diabetic children, and three healthy children scored in the pathological range on the parent questionnaire, as did two, three, and five respectively on the teacher questionnaire and four, four, and eight on the depression inventory. There was no significant difference across the three groups. Analysis of mean scores similarly showed no significant difference across groups. In contrast, the single measure used for younger children showed an increase in behavioural difficulties among the diabetic children.

Conclusion-Haemophiliac children attending the West of Scotland Centre were no more disturbed than their diabetic or healthy peers despite the identification of HIV infection within the clinic and the widespread adverse publicity associated with AIDS and HIV infection.

\section{Introduction}

The care of chronically ill children has progressively supplanted the care and cure of acutely ill children in Western paediatric practice. ${ }^{12}$ Whereas physically healthy children have rates of psychiatric disturbance varying from $6.6 \%$ in the Isle of $\mathrm{Wight}^{3}$ to $17 \%$ in Blackburn ${ }^{+}$chronically ill children may have higher rates, estimated variously at $10.4 \%$ in the Isle of Wight (excluding neurological disorders) to $30 \%$ in Rochester, New York. ${ }^{5}$ Reports on the psychosocial effects of haemophilia are extensive and conflicting. Early descriptive papers drew attention to severe adjustment problems and to such practical difficulties as missed schooling, unemployment, and poor social functioning. ${ }^{6.9}$ Some more recent papers have echoed these findings, ${ }^{1011}$ but others have reported little or no difference between children with haemophilia and the general population on measures of school attendance, social adjustment, and personality. ${ }^{1213}$ We devised this study to determine the prevalence of psychiatric disorder in children with haemophilia attending the West of Scotland Children's Haemophilia Centre.

\section{Method}

The study population comprised children registered with the West of Scotland Children's Haemophilia Centre. When more than one child per family was affected the elder child was taken as the index child for study. Of 61 families registered as having one or more children with haemophilia or other bleeding disorders, $53(86 \%)$ agreed to participate. Of the index children, 30 were diagnosed as having classic haemophilia A, seven had haemophilia $\mathrm{B}, 10$ had von Willebrand's disease, and six had various rarer bleeding disorders.

\section{CONTROLS}

The diabetic clinic, based in the same children's hospital as the haemophilia centre, provided a control group of 51 diabetic children matched to the haemophiliac children by age, sex, social class, and birth order. The use of a diabetic group controlled for the non-specific effects of chronic illness in childhood, thus allowing assumptions to be made about effects specific to haemophilia. A second control group of 49 healthy children was obtained from seven general practices throughout the west of Scotland, reflecting the geographic scatter (urban, coastal, and rural) of the haemophiliac group and matched for age, sex, social class, and birth order. This second control group allowed comparison with healthy peers growing up in similar surroundings.

Matching for both diabetic and healthy control groups was initially achieved by identifying from clinic and practice age-sex registers children who were of the same sex with a birth date within six months of each child with haemophilia. Practice and clinic notes were then used to obtain information about birth order, family size, and father's occupation. Children with a current or previous referral to a psychiatric or psychology clinic were excluded. In the healthy group the matched child and any siblings were also required to be free of any chronic illness and any condition that required attendance at a hospital outpatient clinic in the preceding two years. The first child identified as of correct birth order, family size, and social class who met all these criteria was selected.

\section{ASSESSMENT}

The assessment protocol applied to the families was 